\title{
Inspeção Semiótica do ColabWeb: Proposta de Adaptações para o Contexto da Aprendizagem de Programação
}

\author{
Thais Castro \\ Departamento de Informática \\ Pontifícia Universidade Católica do Rio de Janeiro \\ Departamento de Ciência da Computação \\ Universidade Federal do Amazonas \\ tcastro@inf.puc-rio.br
}

\author{
Hugo Fuks \\ Departamento de Informática \\ Pontifícia Universidade Católica do Rio de Janeiro \\ hugo@inf.puc-rio.br
}

Resumo Este trabalho inaugura uma linha de pesquisa qualitativa aplicada ao contexto da aprendizagem de programação através da avaliação de groupware utilizando um método de inspeção de software baseado em semiótica. Para isso, inicia-se com a descrição do método utilizado, seguido pela inspeção propriamente dita, contendo as reflexões referentes a cada etapa. Ao final, discute-se sobre os problemas encontrados com respeito à comunicabilidade do software, propondo também adaptações para que seja mais bem utilizado pelos usuários finais, neste caso alunos.

Palavras-Chave: aprendizagem de programação em grupo, inspeção semiótica, ambientes virtuais de aprendizagem.

\begin{abstract}
This work starts a new qualitative research line applied on the programming learning context through the groupware evaluation using an inspection method based on semiotic. Therefore, we initially describe the method used. Following, we present the inspection, concerning the reflections for each method step. To end up, we discuss about the problems related to the software communicability, proposing also adaptations in order for the groupware evaluated to be used by its end users, students on this case.
\end{abstract}

Keywords: group programming learning, semiotic inspection, learning management systems 


\section{Introdução}

A necessidade por colaboração está presente no indivíduo desde sua infância, ao transpor suas habilidades individuais e se achar compelido ao trabalho em grupo [11]. Com relação ao mercado de trabalho, é crescente a demanda por equipes capazes de gerenciar e desenvolver seus próprios projetos, sendo que saber colaborar é um importante aliado para o sucesso. Segundo [10], a fórmula é simples: uma equipe que se auto-organiza e onde seus integrantes conseguem colaborar adequadamente assume riscos conscientes, e por isso obtém mais chances no mercado.

A fim de preparar o indivíduo para o mercado de trabalho, além da colaboração, cabe aos cursos de graduação prover os alicerces à busca de novos conhecimentos, pois o mercado de trabalho requer também que o profissional seja capaz de se apropriar das novas tecnologias e métodos de trabalho. Além disso, a colaboração gera efeitos benéficos na educação, a exemplo do que ocorreu com a introdução de um software para registrar refinamentos de soluções de exercícios de programação, trabalho descrito em [1]. No caso do artefato utilizado no trabalho citado, não houve uma preocupação com seu poder de comunicação, pois, segundo os autores, a ênfase do trabalho era nos resultados da aplicação do método clínico com alunos de turmas anteriores da mesma disciplina, parte do currículo dos mesmos cursos.

Após o desenvolvimento do artefato de software supracitado para registro da evolução de códigos, o grupo de pesquisa da Universidade Federal do Amazonas (UFAM) desenvolveu um groupware, o ColabWeb, o qual se destina ao gerenciamento da aprendizagem utilizado em cursos de graduação e pós-graduação presenciais, como ferramenta de apoio. Ainda que não tenha sido alvo de atenção inicial por parte dos desenvolvedores, houve um projeto de interface para o ColabWeb, privilegiando a funcionalidade. Portanto, os primeiros cursos ocorreram, uns com maior aproveitamento de seus recursos e outros com menos. Em vista dessa diferença em termos de sucesso no uso do groupware, evidenciada neste trabalho através do gerenciamento de cursos de computação introdutória, decidiu-se fazer uma inspeção que evidenciasse o poder de comunicação do artefato de software (ColabWeb). Para isso, é utilizado o Método de Inspeção Semiótica (MIS) [6].

Outros métodos de avaliação aplicados a ambientes virtuais de aprendizagem (AVA) já foram utilizados em contextos de curso, como os descritos em [12] que avalia a participação dos alunos em fóruns, [7] que avalia a participação dos alunos de um curso em todas as atividades do groupware utilizado e [13] que avalia a participação em debates. No entanto, nenhum desses trabalhos considera que a interface influencia na avaliação da participação dos alunos nas atividades propostas em um AVA. Tal aspecto só é considerado em métodos de inspeção baseados na semiótica como é o caso do MIS.

Conforme a expectativa do MIS, foram elencadas recomendações de melhorias para a comunicabilidade do ColabWeb. Este trabalho propõe e inaugura uma linha de avaliação de ambientes de aprendizagem com ênfase na comunicabilidade. Avalia-se uma instância (ColabWeb) de uma arquitetura amplamente utilizada (Moodle), observando-se unidades, que neste caso são cursos. A partir dessas unidades generalizam-se as observações para a instância.

\section{A Engenharia Semiótica}

A Engenharia Semiótica propõe uma abordagem para IHC centrada na comunicação, onde o designer dos sistemas computacionais são atores ativos na comunicação com o usuário. Segundo de Souza em [4], enquanto teoria de IHC, as metas da engenharia semiótica são: apresentar uma caracterização de IHC (extensa e distinta); prover uma ontologia consistente da qual podem ser derivados frameworks e modelos, sobre aspectos particulares de IHC; e detalhar restrições epistemológicas e metodológicas, bem como condições aplicáveis ao espectro da pesquisa na qual a teoria possa servir de apoio.

Ao se construir um ambiente computacional, segundo a engenharia semiótica, é necessário refletir sobre a metacomunicação da interface com o usuário. Para isso, é adotado o modelo de funções comunicativas de Jakobson [9] apud [4], o qual propõe funções comunicativas. Estas funções são utilizadas para a construção de artefatos de metacomunicação em IHC. Elas são: o autor, o receptor, o contexto, o canal, o código e a mensagem.

Pode ser que o pesquisador de IHC não queira ou não possa construir um ambiente computacional. Isto ocorre porque seu público alvo (usuários) já utiliza um ambiente ou porque sua instituição adota uma determinada plataforma computacional. Neste caso, é necessário avaliar os elementos de IHC por meio das funções comunicativas que já estão presentes no ambiente, a fim de propor modificações para melhorar a metacomunicação com o usuário ou, se o ambiente atender às funções comunicativas conforme desejado, relatar e registrar esses elementos.

A fim de avaliar o efeito da comunicabilidade dos sistemas computacionais, a engenharia semiótica propõe dois métodos, o Método de Inspeção Semiótica (MIS) [5] e o Método de Avaliação da Comunicabilidade (MAC) [14]. O MIS é utilizado para inspecionar um artefato computacional, considerando o designer como ator ativo através de sua metacomunicação com o usuário, sem a 
necessidade de fazer testes com usuários. Já o MAC propõe uma abordagem mais centrada na utilização do artefato pelo usuário, envolvendo testes com usuários considerando um aspecto de interface. Vale salientar que neste trabalho somente é utilizado o MIS, dada a necessidade de se efetuar uma inspeção geral no artefato, antes de se concentrar em aspectos específicos de sua interface.

\subsection{O Método de Inspeção Semiótica}

Conforme definido em [6], o principal propósito do Método de Inspeção Semiótica (MIS) é avaliar a comunicabilidade de artefatos computacionais interativos. O MIS é, portanto um método que avalia a comunicabilidade, concentrando-se nos significados da interface com o usuário expressos pelo designer. $\mathrm{O}$ método auxilia os inspetores a anteciparem os tipos de consequiência que as escolhas de projeto (design) podem trazer quando usuários reais interagem com o sistema.

O MIS é aplicado em 5 etapas: (i) análise dos signos metalingüísticos, (ii) análise dos signos estáticos, (iii) análise dos signos dinâmicos, (iv) uma comparação entre a mensagem de metacomunicação do designer gerada nos passos anteriores, e (v) uma avaliação final da comunicabilidade do sistema inspecionado.

Antes de se iniciar o MIS propriamente dito, é necessária uma fase de preparação, que envolve um levantamento sobre a documentação existente e uma organização prévia do espaço a ser analisado, por exemplo, a criação de grupos ou inscrição em grupos existentes. Em (i) analisa-se os signos metalingüísticos existentes na documentação, help do sistema ou meta-mensagem na tela. Os signos estáticos analisados em (ii) são aqueles cujo significado é interpretado independentemente das relações temporais e causais, sendo o contexto da interpretação limitado aos elementos presentes na interface em um dado momento. Em (iii) são consideradas as transições na interface, como conseqüências das ações realizadas sobre uma tela. As três primeiras etapas se combinam para transmitir a mensagem de metacomunicação do designer (iv), que pode ser parafraseada ao seguinte esquema:

"Aqui está o meu entendimento de quem você é, o que eu aprendi que você quer ou precisa fazer, em qual jeito você prefere fazer e por que. Este é o sistema que eu projetei pra você e este é o jeito que você pode ou deve usá-lo para satisfazer seus propósitos que casam com esta visão".

Na última etapa do MIS (v) avalia-se a comunicabilidade do sistema, reconstruindo uma mensagem de metacomunicação unificada e julgando os custos e benefícios das estratégias comunicativas identificadas nas etapas anteriores.

O MIS pode ser aplicado a qualquer artefato de software de onde se queira inspecionar o poder de comunicação do designer com o usuário. Para groupware, há preocupações próprias, portanto é necessário se observar outras interações, além das de usuário com designer [3]. Pelo menos um trabalho exemplifica o MIS para groupware, publicado em [8]. A diferença dessas inspeções anteriores para a realizada neste trabalho é quanto à unidade, conforme mencionado anteriormente. Em vez de se avaliar o ColabWeb de forma geral, o cenário de inspeção escolhida conduz à avaliação da metacomunicação em cursos, posteriormente generalizada para o software.

Na próxima seção há uma descrição sobre a utilização do ColabWeb [15] como ferramenta de apoio à aprendizagem de programação introdutória. O ColabWeb é um groupware baseado na arquitetura Moodle, desenvolvido incrementalmente e utilizado para gerenciar artefatos digitais produzidos pelos alunos nas disciplinas de graduação e pós-graduação de computação na Universidade Federal do Amazonas (UFAM).

\section{O Contexto da Aprendizagem de Programação utilizando o Colab- Web}

No primeiro semestre de cada ano acadêmico, são oferecidas quatro turmas da disciplina Introdução à Computação na UFAM para alunos cursando, preferencialmente, o primeiro semestre de seus cursos. Dessas quatro turmas, duas são dirigidas aos alunos do Bacharelado em Ciência da Computação e duas para os alunos de Engenharia da Computação. Ao todo são aproximadamente 110 alunos por semestre.

Há 3 anos começou-se a utilizar ferramentas de apoio para o ensino de Introdução à Computação, devido à grande quantidade de alunos. Como resultado de estudos de caso da utilização dessas ferramentas [1], no terceiro ano foi utilizado o ColabWeb, devido suas funcionalidades de gerenciamento de grupo e conteúdo. Esta última funcionalidade foi necessária, pois segundo a evolução da metodologia adotada no curso, os alunos passaram a ser divididos em grupos para resolverem exercícios de programação. Consequentemente, os alunos se engajaram em outras atividades, como por exemplo, discussões em grupo, escrita cooperativa de relatórios e reflexões sobre os códigos. Para tanto, foram criados 3 cursos no ColabWeb que serão descritos a seguir.

O curso IC-Apoio serve como site de apoio para a disciplina, contendo informações comuns a todas as tur- 
mas, ementa e discussões mais gerais dos alunos, servindo também de socialização entre os alunos dos diferentes cursos. Os outros dois cursos são cursos propriamente ditos: IC-CComputação, com as duas turmas de Ciência da Computação, e IC-EngComputação, com as duas turmas de Engenharia da Computação. Apesar da expectativa de que ambos os cursos fossem uniformemente frequentados, a utilização não foi homogênea, o que será discutido nas próximas sessões.

\section{Inspeção Semiótica do ColabWeb}

Dado que o ambiente ColabWeb é uma instância do ambiente Moodle, foi a partir deste ambiente (http://moodle.org) que foi realizada uma inspeção inicial para se descobrir quem eram seus possíveis usuários na visão do designer, representante da equipe de desenvolvimento do Moodle, e se há documentação suficiente para todos os tipos de usuário que este designer pretende atender. Constatou-se que a documentação, apesar de pouca, era consistente com os propósitos da ferramenta. O Moodle, então, pode ser visto como uma ferramenta para desenvolvedores e que, devidamente estendida, conforma-se com as necessidades específicas de cada instituição que a utiliza.

Como o projeto do Moodle tem como meta fornecer um sistema totalmente configurável para o professor gerenciar seus cursos, há muitos elementos na configuração de cada curso, o que por sua vez requer uma análise minuciosa para avaliar sua adequabilidade. O ColabWeb manteve esses elementos totalmente configuráveis assim como o projeto de interface original. Isso deixa o cenário de inspeção muito amplo e difícil de analisar, necessitando para isso delimitar um escopo.

A fim de se delimitar o escopo da inspeção, o cenário utilizado foi o do curso de programação introdutória ministrado para alunos do primeiro semestre de computação. Para este trabalho foram analisadas quatro turmas do curso, três que já ocorreram durante o semestre acadêmico de 2008.1 e outro desenvolvido como exemplo. Na última etapa do MIS, isto é, na avaliação final, são propostas adaptações, considerando as limitações da arquitetura utilizada. Os cursos analisados (conforme definição do ColabWeb), e utilizados por alunos, professores e monitores, foram: "IC-CComputação", "ICEngComputação" e "IC-Apoio". O curso "EngSemiotica" foi criado com configurações padrão, para que fosse possível observar quais aspectos de qualquer instância do Moodle podem ser modificados.

O cenário de inspeção elaborado foi o seguinte: "Joana é uma aluna recém chegada ao curso de Ciência da Computação e está matriculada na disciplina Introdução à Computação. Nesta disciplina ela vai aprender a programar utilizando Haskell, uma linguagem funcional. As atividades propostas, bem como avisos e notas serão acompanhadas no ambiente computacional ColabWeb. O problema é que ela nunca usou um ambiente gerenciador de cursos e, devido à necessidade de estudar programação, não tem muito tempo de percorrer o ambiente para se acostumar com o esquema de navegação e organização em seu curso. Por outro lado, seu professor criou o curso IC-Apoio no mesmo ambiente, que serve de apoio às atividades propostas no curso IC-CComputação, com informações gerais sobre a disciplina. Ela espera não ficar confusa em ter que utilizar esses dois cursos dentro de um ambiente que não conhece, pois precisa fazer os trabalhos."

\subsection{Etapas do MIS}

As cinco etapas do MIS apresentadas anteriormente na Seção 2.1 serão instanciadas abaixo para o ColabWeb.

\section{Etapa 1 - análise dos signos metalingüísticos}

Nesta etapa é realizada uma inspeção (on-line e offline) na documentação disponível sobre a ferramenta em questão, buscando a meta-mensagem do designer para o usuário. No caso do ColabWeb, não há documentação disponível sobre a ferramenta, somente um artigo científico [15] que discorre sobre a funcionalidade de gerenciamento de grupos, uma extensão ao Moodle original, descrita como “... a percepção dos indivíduos enquanto parte de um ou vários grupos, além da possibilidade de re-organização em subgrupos".

Dado que o ColabWeb herda muitas das restrições e funcionalidades do Moodle, é importante citar a mensagem do designer que aparece na abertura do site do Moodle (traduzido para português): "O Moodle é um Sistema Gerenciador de Cursos (SGC), também conhecido como um Sistema Gerenciador da Aprendizagem (SGA) ou Ambiente Virtual de Aprendizagem (AVA). É uma aplicação web gratuita que educadores podem utilizar para criarem sites de aprendizagem efetivos". Há alguns manuais disponíveis no site, mas conforme consta na descrição transcrita anteriormente o Moodle foi projetado para ser estendido por programadores ou utilizado por instrutores de cursos na web, que ora assumem o papel de administradores de cursos ora de tutores ou professores. Portanto, não há documentação para o usuário final, o aluno. O designer do Moodle entende que isto, a documentação, cabe ao administrador ou professor.

Apesar de o projeto do Moodle não possuir documentação para alunos, no site há alguns exemplos de documentação, entre elas "Moodle: An introductory user guide for students"1. Neste documento, o designer se refere

'http://www.bath.ac.uk/learningandteaching/themes/elearning/guides/moodle/Moodle student guide.pdf 
ao Moodle como uma ferramenta bastante intuitiva e convida o usuário a experimentar o sistema "tente e veja o que acontece" (trad. do autor). Este e os outros exemplos de documentação para o usuário final foram desenvolvidas juntamente com uma instância do Moodle e a presença de uma página de exemplos indica que é isso que o designer do Moodle espera que seus usuários (designers de sites) façam.

Quanto ao ColabWeb, ao se entrar em qualquer curso não há sequer uma "dica" de como proceder, ou do que os ícones significam. Foi observada também a ausência a utilizar ambientes de redes sociais.[O que eu aprendi que você quer ou precisa fazer, de que forma e porque]. Você precisa de um sistema para gerenciar a disciplina que você está matriculado, podendo interagir com outros alunos, resolvendo exercícios e acompanhando as instruções do professor. Você precisa ser capaz de visualizar as atividades de seus colegas e escrever textos em ferramentas auxiliares como wikis, fóruns e chats. [Este é o sistema que eu projetei pra você e essa é a maneira pela qual você pode ou deve utilizá-lo de forma que preencha uma variedade de propósitos que coadunam com esta visão].

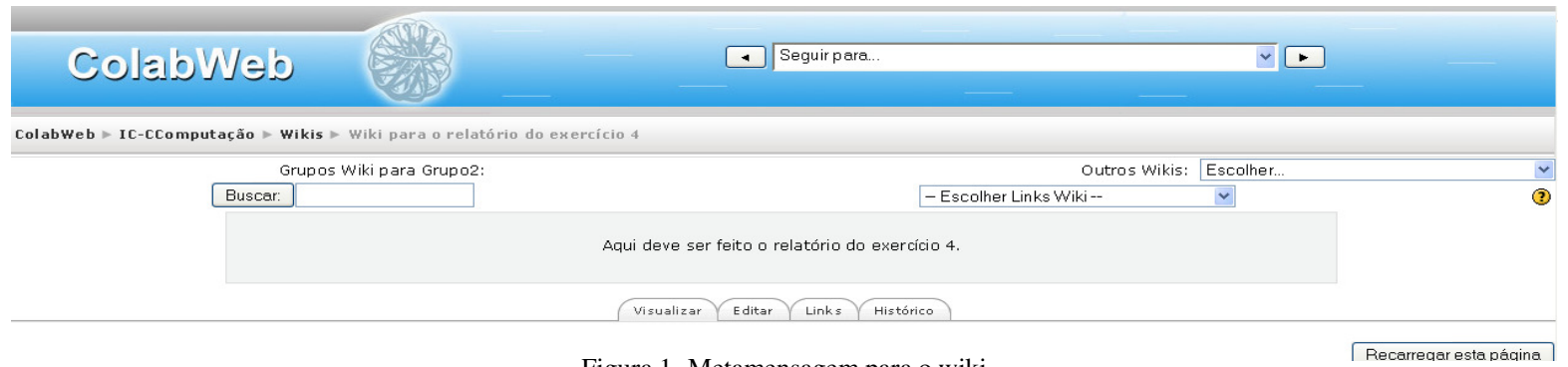

Figura 1- Metamensagem para o wiki

de um help para o usuário. Com relação ao curso ICCComputação há descrições gerais sobre as atividades a serem desenvolvidas feitas pelo professor (designer de curso), como o que consta no wiki para o exercício 4, conforme ilustrado na Figura 1. Os signos metalingüísticos presentes na interface do ColabWeb podem ser muitos ou poucos, dependendo do designer do curso. Nos cursos analisados esses signos quase não existem, com excessão das metamensagens conforme exemplificado na Figura 1.

O MIS sugere que se vá construindo a metamensagem do designer à medida que se conclui cada etapa do método. Esta metamensagem deve ser baseada em um esquema de metacomunicação, descrito na Seção anterior. Em seguida está a metamensagem inicial de comunicação do designer do ColabWeb para seu usuário final (aluno). O
Você pode usar o calendário para verificar os eventos do curso, a estação de percepção para estar a par automaticamente da movimentação em seus outros cursos e ainda subdividir seus grupos em subgrupos, conforme a atividade pretendida.

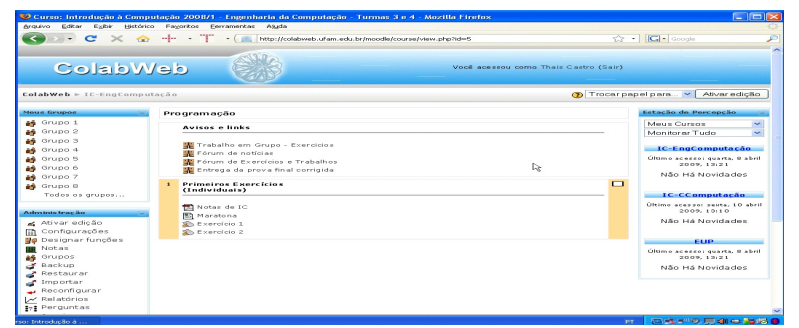

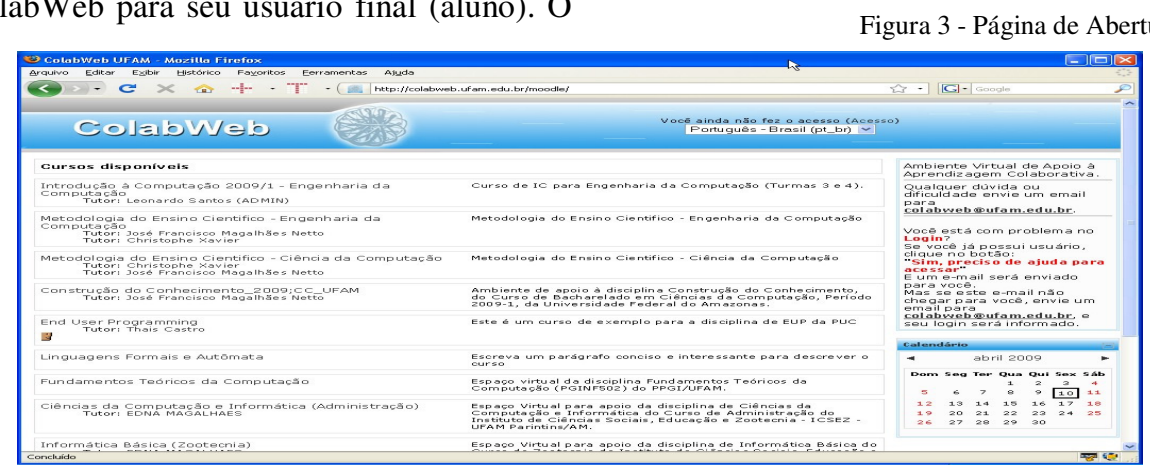

Figura 2 - Predominância da Linguagem Textual

texto entre colchetes é o esquema de metacomunicação.

[Aqui está o meu entendimento sobre quem você é].

Você é um aluno de computação, que já está acostumado 


\section{Etapa 2 - análise dos signos estáticos}

A Figura 2 apresenta a tela de abertura do ColabWeb. A mensagem "login" é substituída pela palavra "acesso", o que não é um jargão muito comum nesses ambientes. Além disso, não é bem comunicada, pois se localiza em cima, entre parênteses e utilizando fonte muito pequena.

Conforme ilustrado na Figura 3, no curso ICCComputação, aparecem inicialmente os grupos existentes, à esquerda, e no centro, em "Grupos" o designer do curso, neste caso o professor, destaca a palavra "importante" para chamar atenção do usuário quanto ao seu grupo. Isto é um bom recurso quando não se consegue eliminar os outros grupos da visão do usuário. À direita, há um recurso chamado estação de percepção [16] monitora as atividades nos cursos que o usuário pertence. As palavras padrão que aparecem, Meus Cursos e Monitorar Tudo são úteis para o seu entendimento. Caso o usuário selecione outra palavra, as caixas abaixo da Estação de Percepção são alteradas

Da mesma forma que o link para entrar no ambiente, o link para sair está muito pequeno. O seu posicionamento é bom, pois aparece centralizado com o nome do ambiente, mas está entre parênteses e utilizando fonte pequena.

A Figura 4 mostra o recurso "Calendário", presente nesse curso. Apesar de útil, marcando as datas ocupadas com algum tipo de atividade, abaixo do calendário aparecem "events key", que por estarem escritos em outro curso, como por exemplo, o tópico do curso abordado naquela atividade.

Em seguida está o refinamento da metamensagem do designer ao final desta $2^{\mathrm{a}}$. etapa, onde o texto entre colchetes é o esquema de metacomunicação do designer, o texto riscado é o que foi retirado e o texto em destaque, o que foi acrescentado.

[Aqui está o meu entendimento sobre quem você é]. Você é um aluno de computação, que já está acostumado a utilizar ambientes de redes-seciais-computacionais.[O que eu aprendi que você quer ou precisa fazer, de que forma e porque]. Seu professor Você precisa de um sis-

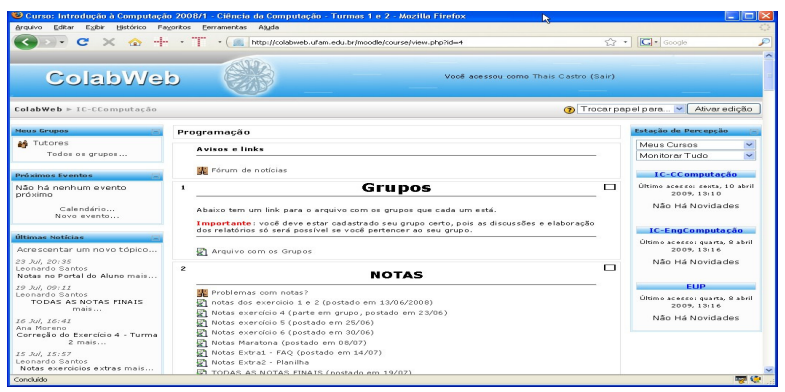

Figura 5 - Perda de Contexto

tema para gerenciar a disciplina que você está matriculado podendo interagir com outros alunos, resolvendo exereícios e acompanhando as instruções do professor e se comunicar com você. Você precisa interagir com os outros alunos de seu grupo, resolvendo exercícios e acom-

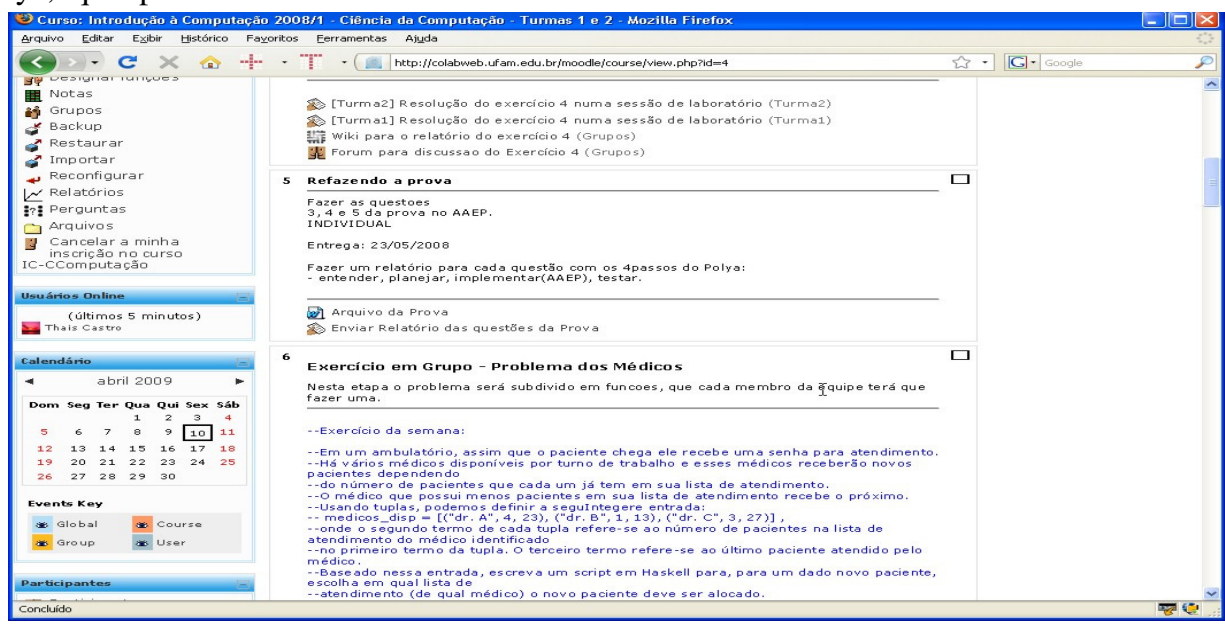

Figura 4 - Recurso Calendário

idioma, confundem o usuário e podem numa última instância tornar o recurso inútil.

A Figura 5 mostra a estruturação de tópicos no curso IC-EngComputação. Neste caso, o professor decidiu organizar o curso por tipos de atividade. Deste modo, ao clicar em uma atividade, o usuário visualiza também as outras atividades do mesmo tipo e perde o contexto do panhando as instruções do professor. Você precisa ser capaz de visualizar as atividades de seus colegas e eserever textos em ferramentas auxiliares come colaborar com eles utilizando wikis, fóruns e chats. [Este é o sistema que eu projetei pra você e essa é a maneira pela qual você pode ou deve utilizá-lo de forma que preencha uma variedade de propósitos que coadunam com esta visão]. Você pode usar o calendário para verificar os eventos do curso, 
a estação de percepção para estar a par automaticamente da movimentação em seus outros cursos e ainda subdividir seus grupos em subgrupos, conforme a atividade pretendida.

\section{Etapa 3 - análise dos signos dinâmicos}

A partir da lista de grupos mostrada na página principal do curso é possível selecionar qualquer grupo em que o usuário esteja inscrito. Esta ação gera uma página como a mostrada na Figura 6. Um primeiro problema é que o usuário vê quem participa em qualquer grupo, inclusive seus logs de acesso. Mais grave é o problema quanto à navegação. O usuário fica perdido, pois precisa selecionar um dos links hierárquicos na parte superior da tela, algo que nem sempre consegue enxergar. Caso selecione grupos, o usuário receberá uma lista com links para grupos, o que é totalmente inútil e confuso visto que o usuário chegou à página atual selecionando um grupo na pá-

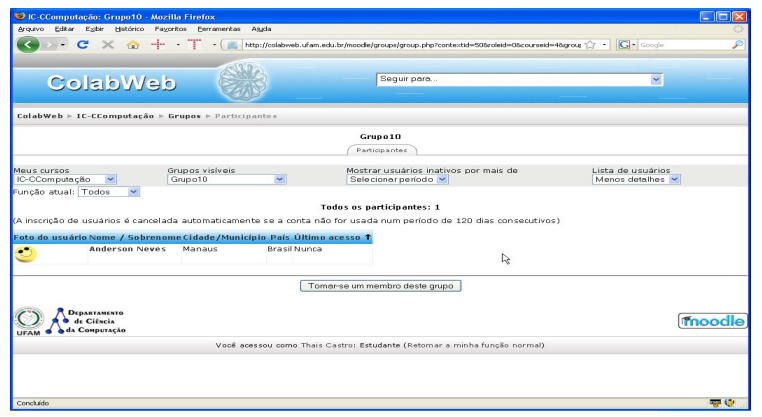

Figura 6 - Visualização de Informações sobre Grupo

gina principal do site do curso (Figura 7).

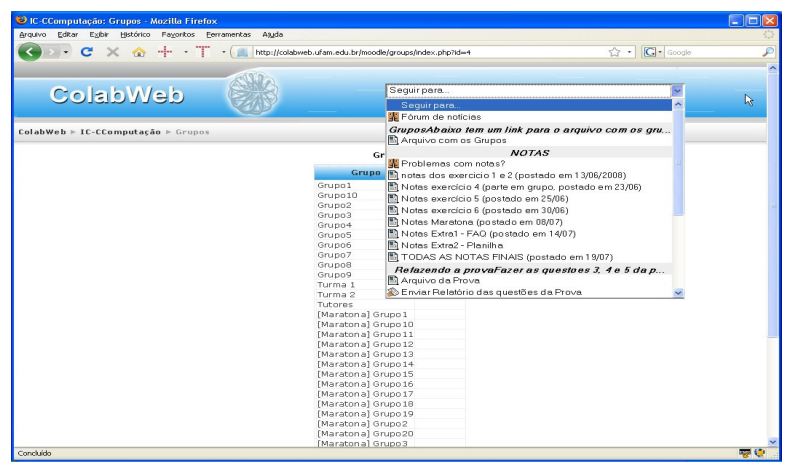

Figura 7 - Navegação nos Grupos

Ainda na Figura 7, a caixa de diálogo "Seguir para..." é de difícil visualização. Caso o usuário consiga enxergála, ele poderá selecionar um dos links que lá aparecem. Isto mitiga o problema da falta de referencial.

$O$ refinamento da metamensagem do designer ao final desta $3^{\mathrm{a}}$. etapa segue a seguir. O que está entre colchetes é o esquema, o que está riscado é o texto retirado e o que está destacado é o que foi acrescentado ao final desta etapa.

[Aqui está o meu entendimento sobre quem você é]. Você é um aluno de computação, que já está acostumado a utilizar ambientes computacionais.[O que eu aprendi que você quer ou precisa fazer, de que forma e porque]. Seu professor precisa de um sistema para gerenciar a disciplina que você está matriculado e se comunicar com você. Você precisa interagir com os outros alunos de seu grupo, resolvendo exercícios e acompanhando as instruções do professor. Além disso, você pode visualizar qualquer atividade de seus colegas, através do link de grupos dentro do curso e depois caminhar pelos links superiores para a parte do ambiente que você quiser ir. Você precisa ser capaz de visualizar as atividades de seus colegas e colaborar com eles utilizando wikis, fóruns e chats. Para isso, você também pode acessar os recursos isoladamente, visualizando todos os daquele tipo. [Este é o sistema que eu projetei pra você e essa é a maneira pela qual você pode ou deve utilizá-lo de forma que preencha uma variedade de propósitos que coadunam com esta visão]. Você pode usar o calendário para verificar os eventos do curso, clicar sobre um evento e ver sua descrição. Pode também modificar suas opções de visualização na estação de percepção, customizando que tipo de movimentação deseja estar ciente ou que cursos deseja acompanhar a movimentação. para estar a par alltomaticamente da movimentaçãa em seus outros cursos e ainda subdividir seus grupos em subgrupos, conforme a atividade pretendida.

\section{Etapa 4 - conclusão do MIS}

A impressão geral sobre a análise dos signos metalingüísticos, estáticos e dinâmicos são focadas na navegação por um usuário final de um curso no ColabWeb. No cenário utilizado, os problemas navegacionais concentram-se nas visualizações das atividades. A especificidade da visualização dos grupos é um exemplo do que ocorre também com outros recursos. Aparentemente, o designer do ColabWeb crê que ao usuário clicar em um determinado fórum, ele estaria interessado em acessar todos os itens daquela categoria, não se dando ao trabalho de consultar antes o usuário, se ele gostaria de ver outros fóruns ou voltar para onde estava.

No caso específico de IC-CComputação o curso foi configurado considerando a ordem cronológica dos exercícios, de acordo com os conceitos trabalhados no curso, o que facilitou a organização das atividades e manteve um padrão navegacional constante e coerente.

Os problemas navegacionais encontrados se referem a qualquer curso criado no ColabWeb, constatado através da criação do curso IC-EngSemiotica. Quanto a problemas específicos nas configurações de cursos, como o que ocorre com o curso IC-EngComputação (Figura 5) isto se 
deve ao fato do ColabWeb herdar do Moodle o amplo esquema de configurações para o professor, o que acarreta em situações muito complicadas.

Para concluir a inspeção, nota-se que a metacomunicação no ColabWeb é eficiente quando o designer de curso é um especialista no uso dessa ferramenta. Porém não é eficiente para os usuários finais, visto que os cursos podem ser organizados de maneiras diversas. Além disso, o usuário se perde com o esquema navegacional, interrompendo sua atividade para retomá-la do ponto onde havia parado. Os usuários do ColabWeb (alunos de computação) normalmente têm a característica de explorar o ambiente para entender seu funcionamento. Para este tipo de usuário o software, apesar de apresentar problemas navegacionais, adequa-se ao propósito. Quanto às permissões de acesso a alguns logs, não é nem um pouco efetiva, pois confunde os usuários, além de violar os direitos dos grupos.

\section{MIS \\ Etapa 5 - avaliação qualitativa dos resultados do}

A triangulação dos resultados na inspeção do ColabWeb é baseada na análise de um chat de propósito geral em IC-Apoio, em wikis de IC-CComputação, no chat do curso IC-Apoio e fóruns em IC-EngComputação. Apesar de se crer que a entrevista sobre os elementos centrais da inspeção é importante, ainda não foi possível entrevistar os alunos que participaram dos cursos em 2008.1, pois os mesmos não responderam aos emails enviados. Foram acrescentadas, então, entrevistas com os professores, sobre comentários específicos de alguns alunos ou algum item que foi detectado no MIS.

Nos registros do ColabWeb, há uma predominância sobre dificuldades relacionadas à conectividade ou demora associada ao carregamento de páginas do ColabWeb. O comentário a seguir, retirado de um fórum do curso ICEngComputação, exemplifica este problema:

"Com 300kbs , a tarde, ta mt complicado de usar o colabweb."

A aluna se refere à velocidade de sua conexão em casa. A equipe de suporte do ColabWeb informou que o problema ocorre no acesso externo à rede metropolitada de pesquisa, uma vez que ficou sujeito a uma grande quantidade desses acessos. O suporte informou também que isto já foi resolvido com a compra de um servidor mais robusto e um pequeno aumento na largura de banda da RNP-AM, onde a UFAM está conectada.

Outro comentário diz respeito ao editor do ColabWeb. De modo geral os editores do ColabWeb não parecem ter um comportamento esperado. Algumas vezes não é possível customizar o texto, conforme reclamação de uma aluna:
"Quando se modifica as cores de um texto, ao inves de mudar somente a parte selecionada, outro pedaço do texto nao selecionado aparece de cor diferente".

A aluna faz uma sugestão:

"Minha opiniao é que trocassem esse editor de texto online. Colocar um mais simples e funcional. Não sei se tem alguem está pretendo usar tantas cores, plano de fundo, smiles(!!), acho pouco provável. Um editor de texto a "la bloco de notas" estaria ótimo".

Sobre o problema de navegação, apontado nas outras etapas do MIS, os professores afirmaram ter recebido muita reclamação por email no início da disciplina, mas depois os alunos se "acostumaram". Ainda segundo os professores, os alunos inscritos no curso ICEngComputação encontraram mais problemas para utilizar o ColabWeb, tanto de localização dos exercícios quanto ao uso dos recursos associados aos exercícios.

Entende-se que os alunos de computação sejam mais acostumados a se adaptarem ao uso de um novo software. Por isso, os problemas navegacionais foram superados, em geral, no início da disciplina. No entanto, eles ocorreram e foram registrados pelos professores. Vale também ressaltar que os alunos do curso IC-EngComputação vivenciaram mais dificuldades em associar recursos a exercícios, o que pode ser constatado em alguns comentários nos fóruns.

O fato de a qualidade da metacomunicação do ColabWeb depender da experiência do designer de curso significa que o sistema é configurável. Como o designer de curso sem experiência, usuário a quem a plataforma Moodle se propõe a auxiliar, não consegue projetar um curso de forma que consiga acompanhar as atividades, utilizando um mínimo de recursos simples e úteis, a metacomunicação do Moodle e, consequentemente, do ColabWeb, é muito pobre.

Os designers do Moodle omitem informações importantes e diretrizes para que o usuário se sinta à vontade de fazer um bom projeto de curso e realizar as atividades da maneira desejada. Isto faz com que os designers do Moodle não consigam atingir seu propósito com a tecnologia, que é, conforme mencionado anteriormente, o de auxiliar o professor (designer de cursos) a projetar um curso semi-presencial ou a distância.

\section{Discussão}

Ao longo deste artigo chamou-se de problemas navegacionais a forma de navegação e estruturação de páginas web do ColabWeb, que é uma herança do Moodle. Nesta sessão, pretende-se discutir sobre os aspectos relacionados a esse esquema de navegação, procurando alternativas para amenizar seus efeitos. 
O Moodle é estruturado em módulos quase independentes, de forma que seja fácil para outros desenvolvedores construírem outros módulos em forma de plugins. Por essa característica, o Moodle é considerado um sistema extensível. Seu esquema navegacional segue a estrutura de diretórios físicos, acompanhando a seqüência de páginas visitadas pelo usuário ao entrar no ambiente. Sendo assim, ao entrar no ColabWeb, aparecem somente os cursos onde o usuário pode entrar. Quando ele seleciona um curso, o designer do sistema que deixá-lo ciente de como fazer para retornar à página anterior, fornecendo um link com o titulo da página ou uma referência ao seu conteúdo. Começa a ficar problemático quando o usuário começa a selecionar outros links dentro do curso e não consegue retornar para onde estava utilizando o mesmo raciocínio.

Para exemplificar, suponha que um usuário do ColabWeb acesse o fórum específico de um exercício. Se ele desistir de fazer comentários ou simplesmente quiser retornar para a página anterior, o link imediatamente anterior não irá produzir o resultado esperado, levando-o à lista de todos os fóruns disponíveis. Neste caso, o designer espera que o usuário saiba que o lugar onde ele estava era IC-CComputação, já que era a página principal do curso.

Para alguns usuários a mensagem do designer está clara, mas para muitos pode confundir, pois a semântica da estrutura de navegação que aparece em forma de links diz respeito à forma como o sistema armazena os dados e não segundo do ponto de vista semiótico.

No contexto em que o ColabWeb foi utilizado, aprendizagem de programação, acredita-se que o sistema não necessite de muitas adaptações para o contexto, pois as atividades de grupo e entrega de códigos e relatórios podem ser desenvolvidas sem prejuízo em um SGC, como o ColabWeb.

\subsection{Proposta de Adaptações}

As sugestões de adaptações e/ou extensões que podem ser desenvolvidas para o ColabWeb, de forma que atenda melhor seus usuários precisam estar de acordo com o que é possível modificar no sistema sem modificar muito a estrutura da arquitetura onde ele está, pois modificações mais profundas trazem efeitos colaterais para o sistema, muitas vezes imprevisíveis. Tendo isso em vista, propõese algumas sugestões quanto ao contexto no qual o sistema foi inspecionado e outras mais gerais, sobre a estrutura navegacional.

Apesar de ser adequado ao uso de alunos aprendendo programação, algumas extensões seriam úteis, como uma ferramenta que fizesse um rastreamento na evolução dos códigos dos grupos para que todos (professores, monitores e alunos) pudessem consultar e aprender sobre as estratégias adotadas para cada situação. No curso de IC-
CComputação os alunos utilizaram uma ferramenta para submissão de códigos, que armazenava todas as versões em um banco de dados. Visto que já há uma ferramenta desenvolvida para acompanhar a evolução dos códigos a partir de um banco de dados [2], isso poderia ser uma extensão aos recursos do ColabWeb.

Uma desvantagem levantada neste artigo foi a abrangência de tipos de configuração para o designer do curso. O Moodle apresenta uma lista muito grande de atividades para configurar. O designer de curso menos experiente, aquele professor que resolve utilizar o sistema como apoio à sua disciplina, sem nunca tê-lo utilizado antes, não consegue nem entender o que são todas aquelas opções. Há opções padrão, mas não há uma explicação sobre elas ou sugestões de como organizar seu curso. Normalmente os designer de curso mantêm a configuração padrão porque é aparentemente mais fácil. No entanto, o padrão do Moodle é um curso com todos os recursos possíveis, cujas atividades são organizadas em Tarefas. Cremos que esta é uma das maneiras mais complicadas de se configurar um curso.

O ColabWeb poderia apresentar uma tela anterior à configuração do curso, na qual o designer perguntasse ao usuário qual seu nível de expertise no sistema. A partir daí, as telas seguintes poderiam apresentar mais ou menos opções de configurações, deixando as outras como padrão. Para aqueles designers de curso com menos experiência seriam apresentadas somente configurações sobre conteúdo, datas e eventos. A interface do curso seria montada com os recursos mais utilizados. Vale ressaltar que isto é possível de ser realizado no ColabWeb, apenas omitindo da tela as informações fornecidas pelo Moodle e fazendo um preenchimento automático das requisições de configuração.

A estrutura de navegação do Moodle não permite ser modificada. No entanto, da mesma forma que as configurações, pode-se omitir os links indesejados da interface com o usuário, acrescentando outro, referenciando assim o desejado. Dessa forma, o problema que ocorre com a visualização de grupos poderia ser amenizado retirando-se o link de grupos, permanecendo somente a palavra que os descreve.

\section{Conclusão}

A comunicabilidade de uma ferramenta de software interfere no sucesso de sua utilização pelo usuário final. Tal influência tende a crescer quando a ferramenta se destina a apoiar o trabalho ou aprendizagem colaborativos. Neste artigo é relatado como, mesmo sob circunstâncias pouco ortodoxas, a aplicação cuidadosa do MIS possibilita a identificação de um conjunto de melhorias para um groupware utilizado num cenário complexo que é o da aprendizagem de programação. Nesse contexto, o 
trabalho desenvolvido buscou contribuir nos seguintes aspectos:

- Para o groupware que foi objeto da investigação:

- através da aplicação do MIS, foi possível identificar e organizar aspectos não documentados do ColabWeb, melhorando o conhecimento sobre seu funcionamento e adequação no contexto de apoio à aprendizagem de programação em grupo

- como parte do trabalho, foi realizada uma análise da interface sob uma perspectiva especializada utilizando um método avaliativo amplamente aceito

- a aplicação do MIS e as reflexões posteriores decorrentes dele, resultaram num conjunto de recomendações para melhoramentos no que diz respeito ao contexto considerado.

- Para as comunidades interessadas (i) no desenvolvimento e utilização de software envolvendo a plataforma Moodle; (ii) no ensino e aprendizagem de programação; e (iii) nos relatos da utilização do MIS - foi apresentado um exemplo de aplicação do MIS em contexto peculiar, onde uma plataforma de serviços, de arquitetura aberta, foi analisada a partir de uma instância aplicada em situação real de uso e foram detectadas possibilidades de melhorias para o produto final (o curso), para a instância da plataforma (ColabWeb) e para a plataforma em si (Moodle).

- No trabalho, ficou evidenciada a importância, na classe de ambientes considerada, do "designer de cursos", e do impacto de sua atuação sob o ponto de vista da Engenharia Semiótica.

- Do mesmo modo, ficou evidenciada a importância dos aspectos de IHC para certos usos de ferramentas de groupware, especialmente ao se considerar os objetivos e estratégias que, no caso da na disciplina observada, mantêm o foco na resolução de problemas e especificação de soluções, requerendo assim a redução de "ruídos" causados por aspectos sintáticos da linguagem de programação utilizada ou por aspectos técnicos das ferramentas de software utilizadas.

Desdobramentos imediatos deste trabalho envolvem a reorganização da ferramenta observada e a conseqüente reaplicação do MIS, indicando um processo de refinamentos sucessivos para um mesmo cenário, além de posterior comparação a outros cursos.

\section{Agradecimentos}

Hugo Fuks recebe bolsas de Produtividade de Pesquisa do CNPq e Cientista do Nosso Estado da FAPERJ. Thais Castro é bolsista do CNPq. Esta pesquisa recebe recursos destinados ao ColabWeb - Proc.553329/2005-7, CNPq/CT-Amazônia n.27/2005 e GroupwareMining Proc.575553/2008-1, CNPq/CT-Amazônia n.055/2008.

\section{Referências}

[1] Almeida N., F. A. ; Castro, T. ; Castro, A. N. "Utilizando o Método Clínico Piagetiano para Acompanhar a Aprendizagem de Programação". In: XVII Simpósio Brasileiro de Informática na Educação, 2006, Brasília. Simpósio Brasileiro de Informática na Educação. Brasília : Gráfica e Editora Positiva Ltda, 2006. v. 17. p. 184-193.

[2] Castro, T.; Fuks, H.; Castro, A. N. "Detecting Code Evolution in Programming Learning". In: 19th Brazilian Symposium on Artificial Intelligence, 2008, Salvador, Bahia. Lecture Notes in Computer Science / Lecture Notes in Artificial Intelligence, v. 5249. p. 145-156. 2008.

[3] De Souza, C. S. "Compulsory Institucionalization: investigating the paradox of computer supported informal social process". Interacting with Computers, v. 16, n. 4, p. 635-656. 2004.

[4] De Souza, C. S. "The Semiotic Engineering of Human-Computer Interaction". MIT Press. ISBN 0-262-04220-7. 2005.

[5] De Souza, C. S., Leitão, C. F., Prates, R. O., da Silva, E. J. "The semiotic inspection method". In Proceedings of VII Brazilian Symposium on Human Factors in Computing Systems (Natal, RN, Brazil, November 19 - 22, 2006). IHC '06, vol. 323. ACM, New York, NY, 148-157. DOI= http://doi.acm.org/10.1145/1298023.1298044. 2006.

[6] De Souza, C. S., Leitão, C. F., Prates, R. O., Bim, S. A. \& da Silva, E. J. "Using the Semiotic Inspection Method in Scientific Research Contexts. Manuscrito não publicado. 2008.

[7] Fuks, H., Cunha, L.M., Gerosa, M.A., Lucena, C.J.P. "Participação e Avaliação no Ambiente Virtual AulaNet da PUC-Rio". In: Silva, M.; Educação Online: Teorias, Práticas, Legislação e Formação Corporativa; Edições Loyola, Rio de 
Janeiro, 2003, ISBN 85-15-02822-0, Cap. 15, pp. 231-254.

[8] Guimarães, F. J. Z., de Souza, C. S. “Análise de um Ambiente de Apoio a Comunidades de Prática utilizando o Método de Inspeção Semiótica”. Monografias em Ciência da Computação, Departamento de Informática, PUC/RJ, n. 06/08. ISSN 0103-9741. 2008.

[9] Jakobson, R. "Linguistics and Poetics". In Style in Language, ed. T.A. Sebeok, 350-377. Cambridge, MA: The MIT Press. 1960.

[10] Pestana, M. C., Pires, P. M. S. G., Funaro, V. M. B. O., Utuyama, A. S., Pacheco, F. M., Guimarães, T. B. N. "Desafios da sociedade do conhecimento e gestão de pessoas em sistemas de informação". In Ciência da Informação, vol.32, no.2. Brasília. Print ISSN 0100-1965. May/Aug. 2003.

[11] Piaget, J. "Sobre a Pedagogia" (1896-1980). Tradução de Cláudia Berliner. São Paulo: Casa do Psicólogo. ISBN 85-7396-035-3.1998.

[12] Pimentel, M., Fuks, H., Lucena, C.J.P. “Avaliação da Participação em Conferências Textuais Assíncronas". Anais Eletrônico do X Workshop de Informática na Escola, integrante do XXIV Congresso da Sociedade Brasileira de Computação (WIE/SBC 2004), ISBN: 85-88442-94-9, 31
Julho - 6 Agosto, Salvador, BA, 2004.

[13] Pimentel, M., Fuks, H., Lucena, C.J.P. “Avaliação da Participação dos Aprendizes em Debates Síncronos”. XIV Simpósio Brasileiro de Informática na Educação - SBIE 2003, 12 a 14 de Novembro de 2003, ISBN: 85-88442-70-1, Rio de Janeiro - RJ, pp. 140-149. 2003.

[14] Prates, R.O., de Souza, C.S., Barbosa, S.D.J. "Communicability Evaluation Method for User Interfaces”. Interactions. New York: , v.7, n.1, p.33 - 38, http://doi.acm.org/10.1145/328595.328608. 2000.

[15] Santos, L. N.; Castro, A. N.; Castro, T. "Alteração no Modelo de Grupos do Moodle para Apoiar a Colaboração". In: XVIII Simpósio Brasileiro de Informática na Educação, 2007, São Paulo. Simpósio Brasileiro de Informática na Educação. Porto Alegre : SBC, v. 1. p. 24-35. 2007.

[16] Spósito, M. A. F.; Castro, T.; Castro, A. N. "Estação de percepção: uma abordagem para o monitoramento em ambientes virtuais de aprendizagem”. In: XIX Simpósio Brasileiro de Informática na Educação, 2008, Fortaleza-CE. Anais do XIX Simpósio Brasileiro de Informática na Educação - SBIE2008. Porto Alegre : Sociedade Brasileira da Computação, p. 288-298. 2008. 